\title{
Development of improved and comprehensive growth and yield models for genetically improved stands
}

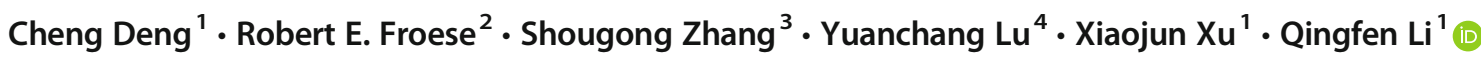

Received: 5 February 2020 / Accepted: 27 August 2020 / Published online: 7 September 2020

(C) INRAE and Springer-Verlag France SAS, part of Springer Nature 2020

\begin{abstract}
- Key message This synthesis of the literature on incorporation of genetic gain into growth and yield models reveals a fundamental challenge associated with the rapid progress in genetics and breeding and limited empirical data on improved stands. Model improvements depend on a better understanding of both the biological basis for gain and of interactions between genetic and non-genetic factors on gain.

- Context Continued development of new genetic varieties of trees requires accurate stand growth and yield models to predict growth trajectories and genetic gain of the new varieties using early-age growth data.

- Aims To identify how the effects of genetic variety on growth and yield models could be analyzed and genetic information could be incorporated into these models for accurate growth simulation and improved yield prediction of genetically improved stands.

- Results Genetic variety may affect one or several of the asymptotic parameters, shape parameters, and rate parameters of growth and yield models, which can be assessed by testing the parameter differences of the models. After determination of the influence of genetic varieties on model parameters and considering the existing general stand growth equation, the genetic gain can be incorporated into growth and yield models by calculation of genetic gain multipliers, adjustment of the site index, and calibration of the new model parameters.

- Conclusion Accurate and effective growth and yield models for genetically improved stands require a better understanding of the effects of genetics, environment, and silviculture measures on tree and stand growth.
\end{abstract}

Keywords Genetically improved stands · Growth difference · Genetic gain · Growth simulation · Yield prediction

\section{Introduction}

Growth and yield models can simulate the natural growth processes of trees, stands, and forests and reflect the impact of management measures on development and condition,

Handling Editor: John M Lhotka

Qingfen Li

1i63757416@163.com

Cheng Deng

dengcheng6618@126.com

Robert E. Froese

froese@mtu.edu

Shougong Zhang

sgzhang@caf.ac.cn

Yuanchang Lu

ylu@ifrit.ac.cn making these effective tools to consider dynamic changes of spatial and temporal stand structure and to accurately predict response to management interventions (Cao and Strub 2008; Pretzsch 2009; Weiskittel et al. 2011; Orellana et al. 2016; Soukhovolsky and Ivanova 2018). Forestry research and

\section{Xiaojun $\mathrm{Xu}$}

xuxiaojun6107@163.com

1 College of Forestry and Landscape Architecture, South China Agricultural University, Guangzhou, China

2 School of Forest Resources and Environmental Science, Michigan Technological University, Houghton, MI, USA

3 Research Institute of Forestry, Chinese Academy of Forestry, Beijing, China

4 Institute of Forest Resource Information Techniques, Chinese Academy of Forestry, Beijing, China 
remarkable advances in data science, mathematical statistics, computing capacity, and modeling approaches have facilitated the development of many computer-based forest growth and yield models (Mustafaa et al. 2011; Cao 2014; Adamec 2015; Fortin et al. 2017). Models take many different forms, including individual equations such as those that describe attributes of trees, stands, or forests; systems of equations that comprise empirical simulators; and concept-driven representations of underlying community of physiological processes (Vanclay 1995; Robinson and Ek 2000; Froese and Robinson 2007). Many different forms of these models have been established and are used widely in forestry (Coops et al. 2012; Collalti et al. 2014; Seely et al. 2015; Njana et al. 2016).

With continued advances in forest genetics and tree breeding, many new genetic varieties have been developed and deployed for forest production (Koskela et al. 2014). Growth and yield models that can accurately reflect the growth characteristics of these genetically improved stands are necessary for several reasons. Accurate predictions of the future volume yield are required by tree breeders to quantify the potential financial payoffs from investment in tree breeding improvement programs, to compare different breeding strategies, and to assign economic weights to selection criteria (Chang et al. 2019). The precise planning of wood flows from a forest estate can greatly enhance the profitability of a forest management enterprise, both to precisely regulate yield and to plan processing facilities, and growth and yield is an essential input. Forest managers also use predictions of stand growth to determine optimum times for thinning, pruning, and felling specific stands and to analyze the economics of silviculture (Goulding 1994).

A critical limitation of most existing growth and yield models is that they are based on data collected in genetically unimproved stands. Although such models are often based on large sample sizes with juvenile and mature trees growing across a wide range of sites (Stoehr et al. 2010), they mainly focus on the effects of forest development (e.g., stand age), site occupancy or tree competition status (e.g., stand density), productive potential (e.g., site quality), and silviculture (e.g., land preparation, fertilization, thinning) on forest growth, without consideration of the genetic factors of the planting material (Sprinz 1987; Sun et al. 2004). Genetically improved stands may have many differences in growth from unimproved stands, such as genetic gain in diameter, tree height, volume, and other traits (Matziris 2005; Vergara et al. 2007). Different varieties may have different growth patterns (Gwaze et al. 2002; Andersson et al. 2006; Gould et al. 2008), stem shapes (profile, taper, etc.), allometry (e.g. tree heightdiameter ratio) (Kroon et al. 2008; Weng et al. 2008; Sharma et al. 2013; Egbäck et al. 2014), and different wood properties (Missanjo and Matsumura 2016; Kimberley et al. 2016; Moore et al. 2017). The use of models based on unimproved stands to predict the future growth and yield of genetically improved stands has greatly limited prediction accuracy and model application, which can adversely affect management decision-making (Adams et al. 2006).

Thus, it is necessary to develop growth and yield models that consider the characteristics of genetically improved materials. These models are essential to guide the scientific management of plantation forests and would be effective tools for the selection and evaluation of genetically improved material, shortening the forest breeding cycle and improving the efficiency and benefit of tree breeding efforts (Wu 1999).

\section{Need for growth and yield models for genetically improved stands}

With the development of tree breeding, there have been parallel efforts to quantitatively study and predict genetic gain. The use of growth and yield models to quantify and predict selection gains during rotation according to early growth differences of various genetic materials can provide another effective strategy for traditional selection of fine seed varieties (genotype, family, and population) and prediction of genetic gains as an alternative to quantitative genetics theory. This approach is simpler and can be more accurate because growth and yield curves effectively average irregularities in the data caused by the measurement error or environmental fluctuation and allow for prediction at ages for which measurements are missing (Rehfeldt 1992; Hamilton and Rehfeldt 1994; Gwaze et al. 2002). Therefore, since the 1980s, forest scientists have begun to study the effects of genetic variety on forest growth and yield models and on the development of these models for genetically improved stands (Nance and Bey 1979; Buford 1989; Schmidtling and Froelich 1993; Danjon 1995).

An increasing number of genetically improved materials are widely used in operational forest management. In addition to the traditional selection of improved material and evaluation of genetic gain, accurate simulation of the growth process of an improved forest and prediction of its response to different treatments are essential for forest management planning and decision-making. For this reason, increased attention has been paid to the development of growth and yield models of genetically improved stands (Wang et al. 2004; Sabatia and Burkhart 2013; Kimberley et al. 2015; Zheng 2017).

\section{Experimental data for growth and yield models of genetically improved stands}

The development and validation or verification of growth and yield models generally require long-term and repeated measures data from permanent sample plots to obtain reliable inferences (Sun et al. 2004; Weiskittel et al. 2011). However, in many practical situations, because of the long rotation length in many forest types and the lag of cultivation behind breeding 
efforts, there are insufficient data from sample plots to reflect the growth of genetically improved stands for an entire rotation (Sun et al. 2004). In order to assess how the offspring of selected parent genotypes perform in a mixture with other genotypes selected for growth, and to see if predicted growth gains persist through rotation, genetic testing has been carried out on a large scale. Many provenances, families, and clonal test plantations have been established for many species around the world since the 1960s (Magnussen and Yeatman 1990; Svensson et al. 1999; Nagamitsu et al. 2018), providing some experimental data to analyze the growth situation and genetic variation of genetically improved materials (Carson et al. 1999; Lambeth 2000; St. Clair et al. 2004).

Given the limited data from the existing provenance, family progeny, or clonal test plantations are not adequate to establish growth and yield models of genetically improved stands, it is often necessary to select good varieties according to the early growth performance to shorten the breeding cycle, and the early selection age is often less than half of the rotation period (Hallingbäck et al. 2018; Cornelius et al. 2018). Therefore, development of a growth and yield model for genetically improved stands may need to be based on the early growth data from test plantations, before maturity. However, it is a significant challenge to deduce the growth and yield of the whole rotation period based on these limited data (Talbert and Hyink 1988).

\section{Establishment of growth and yield models for genetically improved stands}

\subsection{Basic or common strategy}

Due to the insufficient long-term growth data on genetically improved stands, it is currently infeasible to develop entire new empirical models or refit growth equations for most improved forests. Additionally, tree improvement presents a moving target for forest modelers, as a new generation of test plantation is likely to be established before an improved test plantation completes its rotation (Gould and Marshall 2010). To solve these problems, growth survey data from test plantations are used with existing growth and yield equations or model systems based on unimproved stands for growth and yield prediction of genetically improved stands. The most common strategy for genetically improved materials (provenances, families, clones, etc.) has been to first use data from existing test plantations to compare growth differences and evaluate genetic variation and to determine if the relationships of mensurational characteristics (height-age relationship, height-diameter relationship, diameter distribution, etc.) are practically or statistically different. Next, the effects of genetic varieties on the growth and yield of unimproved stands are verified. Finally, specific genetic effect information is incorporated into established growth and yield equations or model systems for unimproved stands to correct the original models for simulation of genetically improved stands. Quantifying any similarities or differences in the effects of genetic factors on tree mensurational characteristics is the first step (Hamilton and Rehfeldt 1994; Nance and Bey 1979; Buford 1989; Schmidtling and Froelich 1993; Danjon 1995).

\subsection{Illustrating essential concepts using the height- age relationship}

The growth differences of genetically improved stands could manifest in changes to various relationships between tree mensurational characteristics. Some examples include the following: (i) the height-age relationship (and for top-height trees, the site index curve), which reflects the dynamic change process of tree height; (ii) the diameter-age relationship, which reflects the dynamic change process of stem basal area; (iii) the height-diameter relationship, which reflects the relationship between diameter classes and average tree height and also reflects the tree stem shape to some extent; (iv) the numberage relationship (survival curve), which reflects the dynamic change of stand density; and (v) the height or diameter distribution, which may indicate differential and nonlinear changes to stand demographics.

Because of the prominence of height modeling in the genetic gain literature and prominence of site index in growth and yield models, we focus on the height-age model in particular in this section, to illustrate some common issues and themes in modeling genetic improvement in trees and stands. There is a close correspondence between site index, volume production, and stand dynamics. As site index integrates many factors, and because height is usually understood to be independent of density (Weiskittel et al. 2011), the height-age relationship can most intuitively reflect the potential growth differences of genetically improved stands even if planted in varied spatial arrangements. For this reason, analysis of height growth difference was the basis for many studies on growth difference analysis of genetically improved stands. For example, Buford and Burkhart (1987) found that the most fundamental effect of genetic factors on forest growth was the change of tree height-age relationship (site index curve), and the most important challenge in predicting the growth of genetically improved stand was to accurately determine this relationship. Joo et al. (2020) compared approaches to model genetic gain in Douglas-fir and concluded that assuming genetic gain differences were represented by site index that produced similar estimates of realized yield gain to more complex modifications of model components involving height and diameter. In many efforts to predict the growth and yield of genetically improved stands, the site index model of a forest growth and yield model system was adjusted to consider genetic effect (provenance effect, family effect, etc.) based on 
the measured effect of genetic factors on the tree height-age curve (Buford 1986; Buford 1989; Knowe and Foster 1989; Danjon 1995).

The Chapman-Richards equation (Richards 1959) is an extremely popular base function for modeling yield of forest attributes in the growth and yield literature. Zeide (1993) and others have explored the underlying biological basis for many growth equations; the utility of these equations has also been clearly demonstrated using empirical data from many published studies that compared alternative basic equation forms. The Chapman-Richards equation can reflect subtle changes in the growth process of genetically improved material due to its flexibility, accuracy, and attractive analytical properties (Pesonen et al. 2009). Furthermore, this equation accommodates a wide range of growth curves, which are typical of empirical data associated with forest research (Yang et al. 2005). The basic form is as follows:

$Y=a \times\left(1-\mathrm{e}^{-b \mathrm{~A}}\right)^{c}+\varepsilon$

where $Y$ is the yield of a characteristic of interest (e.g., height, diameter, volume, or basal area; see, e.g., Smith et al. 2014) at age $A ; a$ is the asymptotic parameter, which represents the asymptotic maximum size of the organism; $b$ is the rate parameter, which represents the intrinsic growth rate; $c$ is the shape parameter, which is related to the power exponent of assimilation; and $\varepsilon$ is a normally distributed zero-expectation random error due to observation of the total growth at age $A$ (Richards 1959). Models of unimproved stands simulated using Eq. (1) have often been used as foundation or core models for growth and yield. In practice, the parameters of the equation can be expanded to introduce more factors (site index, stand density, etc.) to better simulate the growth and yield of stands.

\subsection{Growth and yield differences in genetically improved stands}

The growth differences between improved and unimproved stock can be reflected in the growth equation curves. Taking tree height growth as an example, from the point of view of genetic gain, there are three main classes of differences. First, the genetic gain does not disappear over time, and the growth process (the shape of the growth curve) is the same as that of the unimproved stand (e.g., Gnc in Fig. 1a). In this case, the genetic gain is constant throughout the growth period. For example, if a genetically improved stand has a genetic gain of $10 \%$ for height, its average height at any given age in the rotation period is expected to be $10 \%$ greater than that of the unimproved stand growing in the same environment. Second, the genetic gain does not disappear over time, but the growth process is different from that of the unimproved stand, which indicates the genetic gain is not constant during the growth period, and there may be many variations (e.g., Gn1, Gn2, and Gn3 in Fig. 1a). Third, the genetic gain will disappear over time, which means that the genetically improved stand and the unimproved stand have the same average height at maturity and only differ in growth processes (Fig. 1b).

When the genetic gain does not disappear over time, the coefficients of Eq. (1) vary depending on the growth process. When the genetic gain is constant throughout the growth period, the genetic variety only affects the asymptotic coefficient $a(\mathrm{Gnc}$ in Fig. 1a). When the genetic gain is not constant during the growth period, the genetic variety may affect the asymptotic coefficient $a$ and the rate parameter $b$ ( $\mathrm{Gn} 1$ in Fig. 1a), affect the asymptotic coefficient $a$ and the shape parameter $c(\mathrm{Gn} 2$ in Fig. 1a), or affect all three parameters (Gn3 in Fig. 1a).

\subsection{Testing genetic variety effects on a growth and yield model}

If the difference in growth is significant between the genetically improved stand and the unimproved stand, it is necessary to test if the difference has an effect on components or parameters of growth and yield models. Indeed, growth model parameters may be better indicators of changes in growth patterns associated with improved stands than simple measures like age-specific height, and more likely to be related to mature growth (Gwaze et al. 2002). Genetic improvement may affect multiple parameters in the growth and yield models, resulting in different versions of these models. Two approaches have been commonly used to test if the genetic improvement causes a change in model parameters: the use of dummy variables and including random effects to create mixed-effects models (Callister et al. 2013).

In the dummy variable approach, genetic improvement factors (provenance effects, family effects, etc.) are introduced into the basic model as dummy variables through reparameterization, and then significance tests are performed to determine the effects on each parameter of the model. Equation (1) was expanded as follows to facilitate testing of the statistical hypotheses:

$$
\begin{aligned}
Y= & \left(a_{1} p_{1}+a_{2} p_{2}+\cdots+a_{m} p_{m}\right) \times\left(1-\mathrm{e}^{-b \mathrm{~A}}\right)^{c}+\varepsilon \\
Y= & \left(a_{1} p_{1}+a_{2} p_{2}+\cdots+a_{m} p_{m}\right) \\
& \times\left(1-\mathrm{e}^{-\left(b_{1} \mathrm{p}_{1}+b_{2} p_{2}+\cdots+b_{m} p_{m}\right) \mathrm{A}}\right)^{c}+\varepsilon \\
Y= & \left(a_{1} p_{1}+a_{2} p_{2}+\cdots+a_{m} p_{m}\right) \\
& \times\left(1-\mathrm{e}^{-\left(b_{1} \mathrm{p}_{1}+b_{2} p_{2}+\cdots+b_{m} p_{m}\right) \mathrm{A}}\right)^{\left(c_{1} p_{1}+c_{2} p_{2}+\cdots c_{m} p_{m}\right)}+\varepsilon
\end{aligned}
$$

Where $m$ is the number of genetically improved materials (provenance, family and clone etc.); $a_{i}, b_{i}$, and $c_{i}$ are the asymptotic height parameter, growth rate parameter, and shape 


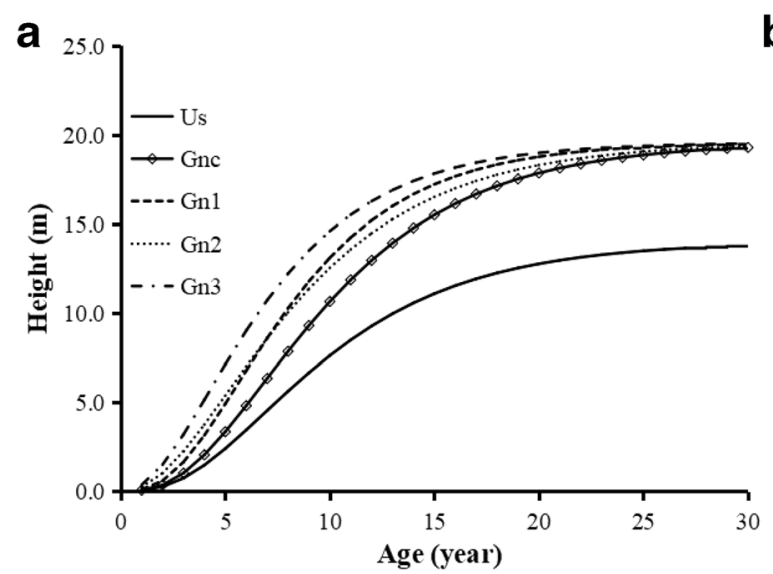

Fig. 1 Conceptual illustration of growth differences of genetically improved stands. a Different patterns where gain persists across time and $\mathbf{b}$ where gain diminishes with time. Us represents the growth process of unimproved stand; Gn means that the initial genetic gain did not disappear over time; Gnc represents the growth process of genetically improved stand which the genetic gain is constant throughout the growth

parameter, respectively, of the genetically improved material $i ; P_{i}$ is the dummy variable, if genetically improved material $i$, $p_{i}=1$, otherwise $p_{i}=0$. For each genetically improved material, the $\mathrm{F}$ test statistic can be used to judge whether genetic improvement has a significant effect on each parameter, that is, to verify the following hypothesis by F-test:

$H_{01}: a_{1}=a_{2}=\ldots=a_{m}, H_{11}:$ at least one $a_{i}$ different;

$H_{02}: b_{1}=b_{2}=\ldots=b_{m}, H_{12}:$ at least one $b_{i}$ different;

$H_{03}: c_{1}=c_{2}=\ldots=c_{m}, H_{13}:$ at least one $c_{i}$ different.

The F-ratio was calculated as follows:

$F=\left(\frac{S S E_{1}-S S E_{0}}{S S E_{0}}\right) \times\left(\frac{d f_{1}-d f_{0}}{d f_{1}}\right)$

where $S S E_{1}$ and $d f_{1}$ are the residual sum of squares and the degrees of freedom, respectively, of the extended model modified to include genetic improvement effects and $S S E_{0}$ and $d f_{0}$ are the residual sum of squares and degrees of freedom, respectively, of the basic model without addition of genetic improvement effect (Nance and Wells 1981; Buford and Burkhart 1987; Tang et al. 2001).

In the mixed-effects model approach, the effect of genetic improvement on the growth and yield model is modeled as a random effect on the parameters of the basic model. Equation (1) was expanded as follows to facilitate testing of the statistical hypotheses of interest:

$$
\begin{aligned}
& Y=\left(a+r_{\mathrm{ai}}\right) \times\left(1-\mathrm{e}^{-b \mathrm{~A}}\right)^{c}+\varepsilon \\
& Y=\left(a+r_{\mathrm{ai}}\right) \times\left(1-\mathrm{e}^{-\left(b+r_{\mathrm{bi}}\right) \mathrm{A}}\right)^{c}+\varepsilon \\
& Y=\left(a+r_{\mathrm{ai}}\right) \times\left(1-\mathrm{e}^{-\left(b+r_{\mathrm{bi}}\right) \mathrm{A}}\right)^{\left(c+r_{\mathrm{ci}}\right)}+\varepsilon
\end{aligned}
$$

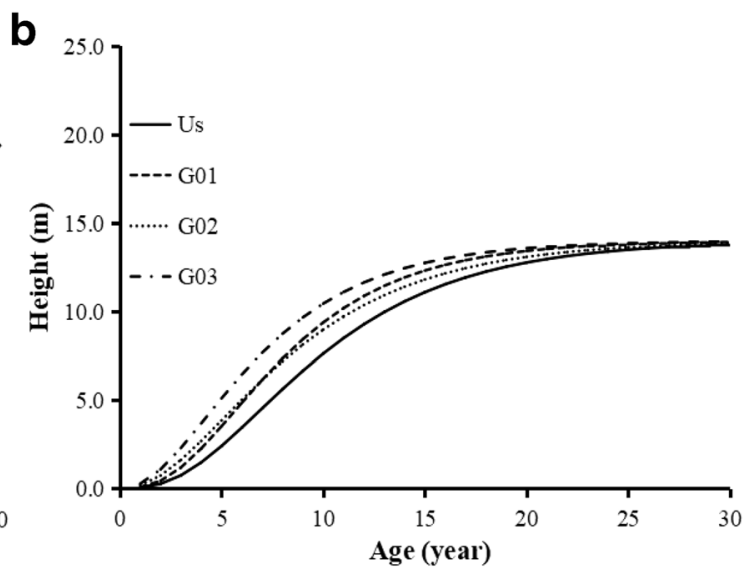

period; $\mathrm{Gn} 1, \mathrm{Gn} 2$, and $\mathrm{Gn} 3$ represent the growth process of genetically improved stand whose genetic gain is varied throughout the growth period; 1, 2, and 3 represent different specific forms; G0 means that the initial genetic gain disappeared over time (equal to zero at maturity); G01, $\mathrm{G} 02$, and $\mathrm{G} 03$ represent the growth process of genetically improved stand which the initial genetic gain disappeared over time

where $a, b$, and $c$ are the fixed-effect parameters and $r_{\mathrm{ai}}, r_{\mathrm{bi}}$, and $r_{\mathrm{ci}}$ are random-effect parameters due to the $i$ th genetically improved material. The effect of the genetic improvement factors on model parameters was investigated by individually excluding the random-effect parameters from the model and evaluating the effect of the exclusion on the overall model fit using the likelihood ratio test (LRT) statistic. Thus, the following hypothesis is tested by the Chi-square test:

$H_{01}: r_{\mathrm{ai}}=0, H_{11}: r_{\mathrm{ai}} \neq 0$;

$H_{02}: r_{\mathrm{bi}}=0, H_{12}: r_{\mathrm{bi}} \neq 0$;

$H_{03}: r_{\mathrm{ci}}=0, H_{13}: r_{\mathrm{ci}} \neq 0$;

The LRT was calculated as follows:

$L R T=2 \log \left(\frac{L}{L_{1}}\right)=2\left[\log \left(L_{0}\right)-\log \left(L_{1}\right)\right]$

where $L_{0}$ and $L_{1}$ are the likelihoods of the basic model without random-effect parameters and the extended model with random-effect parameters, respectively (Fang and Bailey 2001; Sabatia and Burkhart 2013). The same methods can also be used to test the effect of genetic variety on the parameters of other theoretical growth equations.

\subsection{Interpreting parameter differences}

Studies have found complex and varied influences of genetic variety on growth and yield model parameters that were dependent on growth differences of specific tree species, the specific genetically improved materials, and site environmental conditions. For example, using early stand growth measurement data, genetic variants of loblolly pine (Pinus taeda L.) exhibited significantly different asymptotic height and 
shape parameters of a height-diameter curve (Sabatia and Burkhart 2013). At the level of seed source of loblolly pine, the genetic variety was found to affect only the asymptotic height parameter (Nance and Wells 1981; Buford 1986; Buford and Burkhart 1987) or the shape parameter (Sprinz et al. 1989) of a height-age model. At the family levels of loblolly pine, the genetic variety has affected the asymptotic height parameter (Du 1990), as well as the asymptotic height and rate parameters (Knowe and Foster 1989). According to the observations of asymptotic height, Chinese fir (Cunninghamia lanceolata (Lamb.) Hook.) provenances exhibited changed asymptotic parameters of a height model and a basal area model (Tang et al. 2001). Pinus armandi Franch provenances have exhibited different asymptotic height parameters (Wang et al. 2016). At the provenance level of Japanese larch (Larix kaempferi (Lamb.) Carr.), the genetic variety affected the asymptotic height parameter, the rate parameter, and the shape parameter of a height model (Wang et al. 2015). At the family levels of Japanese larch, the genetic variety affected the asymptotic height and shape parameters of a height model (Sun et al. 2005).

Collectively, many studies have suggested that the genetic improvement has significantly affected the asymptotic height parameters of the growth and yield models, with no or little effect on shape and rate parameters. In contrast, a small number of studies have found that the genetic improvement affected both the asymptotic height parameters and shape parameters (or rate parameters) and fewer still found no effects of genetic improvement on the asymptotic height parameters of the growth and yield models, with only effects on the shape parameters (or rate parameters). Thus, it is not simple to predict the effects of genetic improvement to alter specific model parameters, though collectively the results favor the conclusion that the asymptote is most affected. A weakness in many studies is that they present analyses of genetic gain effects on asymptote parameters using datasets where the asymptote is not yet observed. For example, in the loblolly pine data presented by Sabatia and Burkhart (2013), the height is still increasing, though at a decreasing rate, within the range of the training data. Seeking the most faithful empirical representation likely enhances predictive utility for models of genetic improvement. However, in terms of advancing understanding, more rigor in establishing a theoretical model prior to conducting analyses would likely improve the veracity of research results and statistical tests.

\subsection{Incorporation of genetic effects into models for genetically improved stands}

Incorporating genetic effects into growth and yield models for genetically improved stands has most commonly adopted one of three approaches. These are the following: (1) the calculation of specific genetic gain multipliers, (2) manipulation of the site index, and (3) calibration of the model parameters.

In the first approach, the relative difference in growth between genetically improved and unimproved (natural) stands is quantified through genetic gain multipliers. Then, multipliers are used to modify the coefficients of a reference model equation (Rehfeldt et al. 1991; Carson et al. 1999; Gould et al. 2008; Stoehr et al. 2010; Hamilton and Rehfeldt 1994; Gould and Marshall 2010; Kimberley et al. 2015; Haapanen et al. 2016; Ahtikoski et al. 2018). This approach provides a means to extrapolate existing growth models that are a representative of unimproved or average stands using the results of progeny tests or deployment studies (Carson et al. 1999; Gould et al. 2008).

In the second approach, site index manipulation is performed to account for genetic gains based on the height increase at a given age, i.e., by adjustment of the underlying site index assigned to the stand to change the height-age curve of the unimproved growth and yield model system (Buford and Burkhart 1987; Sprinz et al. 1989; Knowe and Foster 1989; Danjon 1995; Gwaze et al. 2002; Xie and Yanchuk 2003). This approach is based on the premise that genetic variety affects only the asymptotic height parameter. In one method the height growth trajectory of a genetically improved stand is estimated from early-age height growth data by adjusting the reference height-age curve by a constant proportion, where height growth trajectories of different genetic varieties are a series of anamorphic height-age curves (Sabatia and Burkhart 2013). The simplest method to represent of genetic improvement may be to simply assume that genetic gain is implicit in site index estimates that obtained a mid-rotation in improved stands (e.g., Joo et al. 2020).

In the third approach to prediction of the growth and yield of a genetically improved stand, parameters that are not affected by genetic improvement are used as global parameters with consistent value across all genetically improved and unimproved stands, and parameters that are significantly affected by genetic improvement are considered additional varietyspecific effects. The model with global parameters is used as a reference model, and this model can be used with early growth survey data of the genetically improved stand to obtain estimates of the parameters that are specific to each genetic variety (Adams et al. 2006; Sabatia and Burkhart 2013; Wang et al. 2015). Depending on the context, the variety-specific effects could be treated as "fixed" or "random" effects (Callister et al. 2013) both for estimating genetic gain and for use in generating model predictions.

These three methods have advantages and disadvantages. In general, the genetic gain multiplier is the simplest and allows model users to utilize incomplete information on the characteristics of trees grown from improved stands (Gould et al. 2008). Multipliers can be used to represent constant and variable genetic gains. For example, a multiplier to the 
asymptote parameter of the yield model (e.g., parameter a in Eq. (1)) represents a constant gain, while a multiplier on the growth parameter (e.g., parameter $\mathrm{c}$ in Eq. (1)) can change the shape, as in Fig. 1b. The use of genetic gain multipliers is currently the most common approach when growth data are insufficient, and this is a viable method to estimate the amount of expected volume gain from tree improvement programs. Projecting stand development with genetic gain multipliers can also provide insight into how genetic gain may interact with other variables such as stand density and site index (Gould and Marshall 2010). However, this approach is still based on individual tree data and relies on accurate model prediction of the average stand (Carson et al. 1999).

Manipulation of site index is straightforward and may integrate effects associated with the adaptability of genetically improved stands to site conditions and interactions with other site or environmental factors. However, increasing the site index alone may not be sufficient if the total increase in volume production is affected by corresponding increases in diameter observed in selected genetically improved stands. Therefore, it may be essential to also consider the heightdiameter relationship when predicting the volume yield of a genetically improved stand using this approach (Stoehr et al. 2010).

Theoretically, calibration of model parameters using empirical data collected from long-term trials has a wider adaptability than the other approaches and can obtain higher estimation accuracy when there is enough supporting data. Clearly, this approach is the most complicated, costly, and time-consuming. Moreover, this approach requires more data or prior information to achieve accuracy comparable with that of reference models from unimproved stands (Sabatia and Burkhart 2013).

In the literature, a compelling case for an optimal approach has yet to be made across a wide variety of studies. This is, at least in a large part, because of the diversity of studies that have had different and often narrowly focused objectives or involve modeling efforts that are constrained by prior decisions to adopt larger frameworks. For example, Kimberley et al. (2015) develop an approach for quantifying gain in radiata pine that was necessary in part because of a change in the accepted rating system for gain, but also in part because of the adoption of a new national-level growth and yield model that superseded prior model efforts and efforts to develop genetic gain multipliers. Joo et al. (2020) found that multipliers in an individual tree model compared favorably to the relatively simple approach of using realized plot-level site index expressed at the most recent re-measurement, which is encouraging. However, the authors also report "striking" changes in relative and absolute gain over 17-21-year measurement periods and 39-43-year simulation periods that suggest significant challenges remain in developing effective modeling and simulation approaches (Joo et al. 2020).

\section{Other factors affecting growth and yield models of genetically improved stands}

There can be a significant variation in the influence of genetic varieties on growth and yield model parameters, and previous studies have reported conflicting results. The conflicting data may be because the biological basis for genetic gain is not well understood, and there is not necessarily a single biological basis for genetic gain. For example, a breeding program may select genotypes with different growth rates but the same asymptotic heights, while another program, perhaps focused on a different species, selects genotypes with different asymptotic heights. Furthermore, the realization of genetic gain is affected not only by the genetic variety itself but also by other nongenetic factors, which can affect the growth and yield of the genetically improved stand (Joo et al. 2020).

In addition to genetic factors, the parameters of stand growth and yield models are influenced by environmental factors that may exhibit different spatial characteristics, such as soil attributes (including soil fertility, texture, moisture, and depth), climate, topography, and wind exposure (Smith et al. 2014). Phenotypic responses of genotypes in different environments are distinct, resulting in differences in stand growth patterns (Fu et al. 1999; Silva et al. 2001; Baltunis et al. 2010; Rohner et al. 2018). Studies have shown that the genetic gain is not consistent across sites; in many cases greater genetic gain is achieved with increased site productivity (Carson et al. 1999; Gould and Marshall 2010), but this is not universal (Martin and Shiver 2002). The maximum projected gains may also occur earlier in the simulation period with increasing site productivity (Gould and Marshall 2010). In some quite extreme sites (such as barren sites), the genetic differences may be poorly expressed (Carson et al. 1999).

Silviculture practices are an additional non-genetic factor affecting the growth and yield of genetically improved stands. Stand density may reflect the degree of space utilization of trees and competition between trees and is always considered an important variable in growth and yield models. Density is clearly affected by decisions about tree planting and by silviculture measures that reduce density, such as thinning. Stand density affects the growth rate and pattern of a stand, as well as the stem height-diameter allometry (Zhang et al. 1997; Cañellas et al. 2004; Adams et al. 2006; Russell et al. 2010; David et al. 2016; Jiang et al. 2016; Egbäck 2016). Further, the stem slenderness, profile, and relative survival of trees are affected by both stand density and genetic variation. Stand density also affects the expression of genetic variation and the realization of genetic gain. For example, some studies have showed that effects of genetic variety on the heightdiameter relationship depended on stand density, with significant effects at higher stand density and no effect at lower density (Sabatia and Burkhart 2013). Thus, different silviculture practices may lead to differences in stand growth and 
yield models (Westfall 1998), and determination of how stand density will affect the growth and survival of genetically improved stands is a critical part of predicting volume gain (Gould and Marshall 2010).

The carrying capacity may play a very important role in accurately modeling genetic gain across an entire commercial rotation. Maximum density may constrain the level of volume gain that can be achieved with improved stands because faster growth may cause stands to reach maximum density more quickly, and gains may be limited if mortality reduces volumes commensurate with gains (Long and Smith 1984). Alternatively, genetic gain may manifest in increased carrying capacity (Joo et al. 2020), which could suggest a reinforcement effect. In addition, fertilization, soil improvement, and drainage can improve the overall site quality and microenvironment, thus affecting the growth rate and process of stands to enhance forest productivity (Kytö et al. 2010).

In living systems, biological traits can confer the ability to alter their phenotypes to better respond to environmental change or developmental signals, during which there must exist a particular set of genes that regulate or reflect such alteration (Gilchrist and Nijhout 2001; Salazar-Ciudad and Jernvall 2010). With the development of molecular biology and bioinformatics, the opportunity may exist to identify the genes that control the height and diameter development of trees (Jiang et al. 2016). Therefore, in the future, non-genetic factors and genetic factors could be combined. Consideration should be given to the influence of non-genetic factors on the expression of these genes, so as to determine the influence of non-genetic factors on the height and diameter growth of genetically improved stands. Ideally, greater understanding of biological or genetic theory would allow mechanisms that drive expression of and change in genetic gain to be built into growth and yield models (Joo et al. 2020).

\section{Improvable aspects of growth and yield models for genetically improved stands}

In the past few decades, there have been many studies involving growth and yield models of genetically improved stands. These studies provided much useful information and tools for more accurate simulation of growth process and prediction of genetic gain. However, while this review found many promising results in recent work, much remains uncertain, and there is no consensus view on the best way forward for modeling genetic improvement. Still, due to various constraints, there are several aspects that can be improved for greater model accuracy.

First, the effect of genetic differences in height, diameter, taper, and other traits at the individual tree level and competitive ability on a stand level should be evaluated. The experimental data utilized in most studies were not obtained from the actual stands but from a separate test plantation (provenance trial, progeny trial, or clone trial stands) used in the genetic testing and selection programs (Kimberley et al. 2015). Thus, the competitive ability of improved strains has typically not been addressed because growth and yield models have instead focused mainly on the genetic contributions of individual tree traits (Adams et al. 2006). Test plantations typically use single-tree plots or small multiple-tree (generally 4-16) row plots. These designs allow high precision for the partitioning of additive genetic variance, for efficient rankings of genotypes, but do not provide adequate estimates of gain under operational conditions of inter-tree competition. A typical test plantation includes a large number of genotypes, where both high and low performers are grown together (Carson et al. 1999). In contrast, a typical genetically improved stand will contain a mix of offspring, but only from the very highest performers (Carson et al. 1999). Single-tree plot designs can magnify family differences due to the effects of competition among trees (Magnussen 1989), but in row plots, members of the same varieties (provenance, family, and clone) have increased probability of sampling the same microenvironment, thus reducing estimates of environmental variation (Magnussen 1993). This can cause overestimation of heritable improvements and gain in growth traits (Dhakal and White 1996; Vergara et al. 2004; Terrance et al. 2010). Stand-level competition has a profound effect on growth and final tree size, so predicting gain using only data from a test plantation in the selection program may not represent actual realized gains in yield, making less accurate predictions (Carson et al. 1999; Adams et al. 2006; Vergara et al. 2007; Kimberley et al. 2015). It is better to compare improved and unimproved stand planted as large block plots for more accurate prediction of changes in growth and yield, as these designs better represent actual stands and can largely eliminate potential competition effect from trees of differing genetics (Carson et al. 1999; Stoehr et al. 2010; Terrance et al. 2010; Kimberley et al. 2015, Joo et al. 2020).

The effects of genetic gain are sometimes subtle and multivariate, affecting several mensurational characteristics simultaneously, nonlinearly, at different scales, and in interaction with site and environmental factors. Yet many growth and yield models focus on a few focal tree mensurational characteristics and lack sophistication to capture interactions. Most simulation models have focused mainly on genetic gain selection indexes such as tree height and diameter, because these metrics are easy to measure and important to forest yield and, therefore, they are the most frequently used indicators for early selection. In turn, these measurements are often the only data, other than survival, available from tree breeding programs that can be used for modeling. Overall, more attention has focused on the effects of different genetic materials on the height-age relationship (site index), height-diameter relationship, and the modification of existing general stand models to reflect the genetic gain of improved stands, with less attention paid to tree height and diameter distributions, basal area growth, crown width, and 
biomass models, or the relationships between various models (Sun et al. 2004). Genetics obviously has significant effects on height, diameter, and survival rate (Sharma et al. 2013; Ye et al. 2010), but genetic factors may affect diameter and height development disproportionally, thus affecting the stem shape and profile (Sabatia and Burkhart 2013). Genetics also can have a significant effect on height distributions and tree size distributions (Weng et al. 2010; Sabatia and Burkhart 2013). Stand volume yield is affected by all these factors simultaneously. This implies that height growth, diameter growth, the heightdiameter relationship, and mortality models must be considered wholistically to obtain accurate prediction of gain in stem volume (Carson et al. 1999). In addition, consideration of the effect of genetic varieties on biomass allocation is also needed to accurately reflect any differences in ecosystem services such as carbon sequestration in genetically improved stands (Aspinwall et al. 2012). Many references have emphasized the need for such work, but thus far no comprehensive study has been reported (Adams et al. 2006).

Genetic improvement factors, site conditions, silviculture measures, and the interaction of these factors must also be considered simultaneously as factors affecting growth and yield. In practical application, genetically improved stands would be planted at different sites, and the planting density and management measures would differ depending on the purpose of cultivation. In contrast, test plantations have limited scope and lack an operational objective, so simulations using data from a test plantation do not fully reflect potential impacts of site quality, silviculture measures, and genetic improvement factors on operational realization of genetic gain (Talbert and Hyink 1988; Carson et al. 1999; Stoehr et al. 2010; Joo et al. 2020). Gene expression and realized genetic gain are affected not only by the characteristics of the genetic material itself but also by the site conditions and management measures (Hamilton and Rehfeldt 1994; Fu et al. 1999; Silva et al. 2001; Egbäck 2016). Importantly, these factors do not work alone but work together to influence the overall growth and development of the stand, with potential interactive effects (Wu and Matheson 2005; Rubilar et al. 2018; Resende et al. 2018). Without consideration of all these effects on stand growth, the application scope and prediction accuracy of growth and yield models for actual production will be limited. Therefore, future work to develop growth and yield models for genetically improved stands will require greater understanding of genetic factors, site environment, cultivation measures, and their interactions for more rational assessment of costly genetically improved stocks for different sites (Sabatia and Burkhart 2013; Kimberley et al. 2015).

\section{Conclusion}

Growth and yield models are essential tools for operational stand and forest management. Where genetically improved trees are deployed, models clearly need to be adapted to capture the effect of genetic improvement. Moreover, models themselves have been effective frameworks for quantifying genetic gain, by allowing for tests of different parameters to reveal differences that are isolated from noise where there is sufficient data. Despite decades of research and many successes, no clear consensus has emerged in the literature on the optimal strategy for refining models to represent genetic gain. However, from the literature, several insights can help guide model development in the future.

Due to the lack of long-term data for improved stands, and the rapid pace of breeding programs, development of new empirical models and the refitting of growth equations for improved forests may never be an effective strategy. Still, the importance of long-term data from improved and unimproved stands planted as large block plots is required, as this simulates actual stands in operational forestry. Past modeling efforts based on early observations should be reevaluated as growth data are accumulated to guide model evolution and efforts with new genetic varieties that have limited data. Long-term data are also essential so that asymptotes (as in height-age) can be observed instead of approximated.

As research proceeds in genetics and on the biological basis for genetic gain, it seems likely that this will provide new insights into how to adapt models to capture more complexity and thus better simulate genetic gain. Some literature has suggested that modelers pay more attention to theory in rationalizing modeling efforts. Future growth and yield simulation systems should be able to predict most tree mensurational characteristics, including complex factors such as volume, which is affected by tree height, but also diameter, taper, vigor, and survival and interactions among trees within stands that capture both competition and environmental influences. Overall, the development of improved and robust growth and yield models for genetically improved stands may simply require more research in operational contexts, to develop a more comprehensive understanding of the effects of genetic, environment, and silviculture measures' interactions on tree and stand growth.

Acknowledgments We appreciate the editors and anonymous reviewers for their constructive comments.

Authors' contributions Conceptualization: CD, SZ, and YL. Writing (original draft): CD. Literature searching: QL and XX. Writing (review and editing): QL and REF. Funding acquisition: YL. All authors have read and approved the content of the manuscript.

Funding This research was funded by the Central Public-Interest Scientific Institution Basal Research Fund for Chinese Academy of Forestry (grant number IFRIT201501).

Data availability Data sharing not applicable to this article as no datasets were generated or analyzed during the current study. 


\section{Compliance with ethical standards}

Conflict of interest The authors declare that they have no conflict of interest.

\section{References}

Adamec Z (2015) Comparison of linear mixed effects model and generalized model of the tree height-diameter relationship. J For Sci 61(10):439-447

Adams JP, Matney TG, Land SB Jr, Belli KL, Duzan HW Jr (2006) Incorporating genetic parameters into a loblolly pine growth-andyield model. Can J For Res 36(8):1959-1967

Ahtikoski A, Haapanen M, Hynynen J, Karhu J, Kärkkäinen K (2018) Genetically improved reforestation stock provides simultaneous benefits for growers and a sawmill, a case study in Finland. Scand J For Res 33(5):484-492

Andersson B, Elfving B, Persson T, Ericsson T, Kroon J (2006) Characteristics and development of improved Pinus sylvestris in northern Sweden. Can J For Res 37(1):84-92

Aspinwall MJ, Mckeand SE, King JS (2012) Carbon sequestration from 40 years of planting genetically improved loblolly pine across the Southeast United States. For Sci 58(5):446-456

Baltunis BS, Gapare WJ, Wu HX (2010) Genetic parameters and genotype by environment interaction in Radiata pine for growth and wood quality traits in Australia. Silvae Genetica 59(1-6):113-124

Buford MA (1986) Notes: height-diameter relationships at age 15 in loblolly pine seed sources. For Sci 32(3):812-818

Buford MA (1989) Mean stem size and total volume development of various loblolly pine seed sources planted at one location. Can J For Res 19(3):396-400

Buford MA, Burkhart HE (1987) Genetic improvement effects on growth and yield of loblolly pine plantations. For Sci 33(3):707-724

Callister AN, England N, Collins S (2013) Predicted genetic gain and realised gain in stand volume of Eucalyptus globulus. Tree Genet Genomes 9:361-375

Cañellas I, Del Río M, Roig S, Montero G (2004) Growth response to thinning in Quercus pyrenaica Willd. coppice stands in Spanish central mountain. Ann For Sci 61(3):243-250

Cao QV (2014) Linking individual-tree and whole-stand models for forest growth and yield prediction. The For Ecosyst 1(3):1-8

Cao Q, Strub M (2008) Evaluation of four methods to estimate parameters of an annual tree survival and diameter growth model. For Sci 54(6):617-624

Carson SD, Garcia O, Hayes JD (1999) Realized gain and prediction of yield with genetically improved Pinus radiata in New Zealand. For Sci 45(2): 186-200

Chang WY, Wang S, Gaston C, Cool J, An H, Thomas B (2019) Economic evaluations of tree improvement for planted forests: a systemic review. BioProducts business, pp 1-14

Collalti A, Perugini L, Santini M, Chiti T, Nolè A, Matteucci G, Valentini $\mathrm{R}$ (2014) A process-based model to simulate growth in forests with complex structure: evaluation and use of 3D-CMCC forest ecosystem model in a deciduous forest in Central Italy. Ecol Model 272: $362-378$

Coops NC, Waring RH, Hilker T (2012) Prediction of soil properties using a process-based forest growth model to match satellitederived estimates of leaf area index. Remote Sens Environ 126: 160-173

Cornelius JP, Pinedoramírez R, Montes CS, Ugarte-Guerra J, Weber JC (2018) Efficiency of early selection in Calycophyllum spruceanum and Guazuma, two fast-growing timber species of the Peruvian Amazon. Can J For Res 48(4):1-7
Danjon F (1995) Observed selection effects on height growth, diameter and stem form in maritime pine. Silv Genet 44:10-19

David HC, Arce JE, Netto SP, Corte APD, Marinheski Filho A, Araújo EJGD (2016) Thinning and site quality effects on the heightdiameter relationship of Pinus taeda. Floresta e Ambiente 23(2): 220-228

Dhakal LP, White TL (1996) Hodge GR. Realized genetic gains from slash pine tree improvement. Silvae Genetica 45(4):190-196

$\mathrm{Du}$ W (1990) Incorporating genetic effects into a forest growth and yield model. University of Idaho, Idaho

Egbäck S (2016) Growth of genetically improved stands of Norway spruce, scots pine and loblolly pine. Swedish University of Agricultural Sciences, Alnarp

Egbäck S, Bullock BP, Isik F, McKeand SE (2014) Height-diameter relationships for different genetic planting stock of loblolly pine at age 6. For Sci 61(3):424-428

Fang Z, Bailey RL (2001) Nonlinear mixed effects modeling for slash pine dominant height growth following intensive silvicultural treatments. For Sci 47(3):287-300

Fortin M, Robert N, Manso R (2017) Uncertainty assessment of largescale forest growth predictions based on a transition-matrix model in Catalonia. Ann For Sci 73(4):1-13

Froese RE, Robinson AP (2007) A validation and evaluation of the prognosis individual-tree basal area increment model. Can J For Res 37: 1438-1449

Fu YB, Yanchuk AD, Namkoong G (1999) Spatial patterns of tree height variations in a series of Douglas-fir progeny trials: implications for genetic testing. Can J For Res 29(6):714-723

Gilchrist MA, Nijhout HF (2001) Nonlinear developmental processes as sources of dominance. Genetics 159:423-432

Gould PJ, Marshall DD (2010) Incorporation of genetic gain into growth projections of Douglas-fir using ORGANON and the forest vegetation simulator. West J Appl For 25(2):391-401

Gould P, Johnson R, Marshall D, Johnson G (2008) Estimation of genetic-gain multipliers for modeling Douglas-fir height and diameter growth. For Sci 54(6):588-596

Goulding CJ (1994) Development of growth models for Pinus radiata in New Zealand - experience with management and process models. For Ecol Manag 69(1-3):331-343

Gwaze D, Bridgwater F, Williams C (2002) Genetic analysis of growth curves for a woody perennial species, Pinus taeda L. Theor Appl Genet 105(4):526-531

Haapanen M, Hynynen J, Ruotsalainen S, Siipilehto J, Kilpeläinen M (2016) Realised and projected gains in growth, quality and simulated yield of genetically improved scots pine in southern Finland. Eur J For Res 135(6):997-1009

Hallingbäck HR, Högberg KA, Säll H, Lindeberg J, Johansson M, Jansson G (2018) Optimal timing of early genetic selection for sawn timber traits in Picea abies. Eur J For Res 137(4):1-12

Hamilton DA, Rehfeldt GE (1994) Using individual tree growth projection models to estimate stand-level gains attributable to genetically improved stock. For Ecol Manag 68(2-3):189-207

Jiang L, Ye M, Zhu S, Zhai Y, Xu M, Huang M, Wu R (2016) Computational identification of genes modulating stem heightdiameter allometry. Plant Biotechnol J 14(12):2254-2264

Joo S, Maguire DA, Jayawickrama KJS, Ye TZ, St. Clair JB (2020) Estimation of yield gains at rotation-age from genetic tree improvement in coast Douglas-fir. For Ecol Manag 466:117390 (available online)

Kimberley MO, Moore JR, Dungey HS (2015) Quantification of realised genetic gain in radiata pine and its incorporation into growth and yield modelling systems. Can J For Res 104(2):1-40

Kimberley MO, Moore JR, Dungey HS (2016) Modelling the effects of genetic improvement on radiata pine wood density. N Z J For Sci 46(1):8 
Knowe SA, Foster GS (1989) Application of growth models for simulating genetic gain of loblolly pine. For Sci 35(1):211-228

Koskela J, Vinceti B, Dvorak W, Bush D, Dawson IK, Loo J, Kjaer ED, Navarro C, Padolina C, Bordács S, Jamnadass R, Graudal L, Ramamonjisoa L (2014) Utilization and transfer of forest genetic resources: a global review. For Ecol Manag 333:22-34

Kroon J, Andersson B, Mullin TJ (2008) Genetic variation in the diameter-height relationship in Scots pine (Pinus sylvestris). Can J For Res 38:1493-1503

Kytö M, Niemelä P, Annila E, Varama M (2010) Effects of forest fertilization on the radial growth and resin exudation of insect-defoliated Scots pines. J Appl Ecol 36(5):763-769

Lambeth C (2000) Realized genetic gains for first generation improved loblolly pine in 45 tests in coastal North Carolina. South J Appl For 24(3):140-144

Long JN, Smith FW (1984) Relation between size and density in developing stands: a description and possible mechanisms. For Ecol Manag 7(3):191-206

Magnussen S (1989) Effects and adjustments of competition bias in progeny trials with single-tree plots. For Sci 35(2):532-547

Magnussen S (1993) Bias in genetic variance estimates due to spatial autocorrelation. Theor Appl Genet 86(2-3):349-355

Magnussen S, Yeatman CW (1990) Predictions of genetic gain from various selection methods in open pollinated Pinus banksiana progeny trials. Silvae Genetica 39(324):140-153

Martin SW, Shiver BD (2002) Impacts of vegetation control, genetic improvement and their interaction on loblolly pine growth in the southern United States - age 12 results. For Sci 26(1):37-42

Matziris D (2005) Genetic variation and realized genetic gain from black pine tree improvement. Silvae Genetica 54(3):96-104

Missanjo E, Matsumura J (2016) Genetic improvement of wood properties in Pinus kesiya Royle ex Gordon for sawn timber production in Malawi. Forests 7(11):253

Moore JR, Dash JP, Lee JR, McKinley RB, Dungey HS (2017) Quantifying the influence of seedlot and stand density on growth, wood properties and the economics of growing radiata pine. Forestry 91(3):327-340

Mustafaa YT, Tolpekin V, Stein A (2011) Application of the EMalgorithm for Bayesian network modelling to improve forest growth estimates. Procedia Environ Sci 7(7):74-79

Nagamitsu T, Matsuzaki T, Nagasaka K (2018) Provenance variations in stem productivity of 30-year-old Japanese larch trees planted in northern and central Japan are associated with climatic conditions in the provenances. J For Res 23(5):270-278

Nance WL, Bey CF (1979) Incorporating genetic information in growth and yield models. In: Proc south for. Tree Improvement Conference, Starkville, pp. $140-148$

Nance WL, Wells OO (1981) Site index models for height growth of planted loblolly pine (Pinus taeda L.) seed sources. Proceedings of the 16th southern forest tree improvement conference. Southern Forest tree improvement committee, Blacksburg, VA, pp 86-96

Njana MA, Bollandsås OM, Eid T, Zahabu E, Malimbwi RE (2016) Above-and belowground tree biomass models for three mangrove species in Tanzania: a nonlinear mixed effects modelling approach. Ann For Sci 73(2):353-369

Orellana E, Filho AF, Netto SP, Vanclay JK (2016) Predicting the dynamics of a native Araucaria forest using a distance-independent individual tree-growth model. Forest Ecosystems 3(1):12

Pesonen A, Eerikäinen K, Maltamo M, Tahvanainen T (2009) Models for predicting tree and stand development on larch plantations in Hallormsstaeur, Iceland. New For (Dordr) 37(1):63-83

Pretzsch H (2009) Forest growth models. In: Forest Dynamics, Growth and Yield. Springer, Berlin

Rehfeldt GE (1992) Early selection in Pinus ponderosa: compromises between growth potential and growth rhythm in developing breeding strategies. For Sci 38(3):661-677
Rehfeldt GE, Wykoff WR, Hoff RJ, Steinhoff RJ (1991) Genetic gains in growth and simulated yield of Pinus monticola. For Sci 37:326-342

Resende RT, Soares AAV, Forrester DI, Marcatti GE, Santos ARD, Takahashi EK, Silva FFE, Grattapaglia D, Resende MDV, Leite HG (2018) Environmental uniformity, site quality and tree competition interact to determine stand productivity of clonal Eucalyptus. For Ecol Manag 410(76):76-83

Richards FJ (1959) A flexible growth function for empirical use. J Exp Bot 10(2):290-301

Robinson AP, Ek AR (2000) The consequences of hierarchy for modeling in forest ecosystems. Can J Forest Res 30:1837-1846

Rohner B, Waldner P, Lischke H, Ferretti M, Thürig E (2018) Predicting individual-tree growth of central European tree species as a function of site, stand, management, nutrient, and climate effects. Eur J For Res 137:29-44

Rubilar RA, Allen HL, Fox TR, Cook RL, Albaugh TJ, Campoe OC (2018) Advances in silviculture of intensively managed plantations. Curr For Rep 4(1):23-34

Russell MB, Amateis RL, Burkhart HE (2010) Implementing regional locale and thinning response in the loblolly pine height-diameter relationship. South J Appl For 34(1):21-27

Sabatia CO, Burkhart HE (2013) Height and diameter relationships and distributions in loblolly pine stands of enhanced genetic material. For Sci 59(3):278-289

Salazar-Ciudad I, Jernvall J (2010) A computational model of teeth and the developmental origins of morphological variation. Nature 464: 583-U138

Schmidtling RC, Froelich RC (1993) Thirty-seven year performance of loblolly pine seed sources in eastern Maryland. For Sci 39(4):706721

Seely B, Welham C, Scoullar K (2015) Application of a hybrid forest growth model to evaluate climate change impacts on productivity, nutrient cycling and mortality in a montane forest ecosystem. PLoS One 10(8):e0135034

Sharma S, Adams JP, Schuler JL, Bragg DC, Ficklin RL (2013) Genetic effects on early stand development of improved loblolly pine (Pinus taeda L.) seedlings. In: Cunningham MW (ed) Proceedings of the 32nd southern forest tree improvement conference; 2013 June 10 13; Clemson, SC, Sponsored publication no, vol 54. Southern Forest Tree Improvement Committee, Clemson, pp 30-35

Silva JCE, Dutkowski GW, Gilmour AR (2001) Analysis of early tree height in forest genetic trials is enhanced by including a spatially correlated residual. Can J For Res 31(11):1887-1893

Smith BC, Bullock BP, Isik F, McKeand SE (2014) Modeling genetic effects on growth of diverse provenances and families of loblolly pine across optimum and deficient nutrient regimes. Can J For Res 44:1453-1461

Soukhovolsky V, Ivanova Y (2018) Modeling production processes in forest stands: an adaptation of the Solow growth model. Forests 9(7):391

Sprinz PT (1987) Effects of genetically improved stands on growth and yield principles. Opt Commun 233(s 4-6):425-430

Sprinz PT, Talbert CB, Strub MR (1989) Height-age trends from an Arkansas seed source study. For Sci 35(3):677-691

St. Clair JB, Mandel NL, Jayawickrama KJS (2004) Early realized genetic gains for coastal Douglas-fir in the northern Oregon cascades. West J Appl For 19(3):195-201

Stoehr M, Bird K, Nigh G, Woods J, Yanchuk A (2010) Realized genetic gains in coastal Douglas-fir in British Columbia: implications for growth and yield projections. Silvae Genetica 59(1-6):223-233

Sun X, Zhang S, Li F, Tan X (2004) An overview on growth and yield projection models for genetically improved stands. For Res 17(4): 525-532

Sun X, Zhang S, Kong F, Sun X (2005) Analyzing parameters of heightage models for open-pollinated Japanese larch families. Sci Silvae Sin 41(1):78-84 
Svensson JC, Mckeand SE, Allen HL, Campbell RG (1999) Genetic variation in height and volume of loblolly pine open-pollinated families during canopy closure. Silvae Genetica 48(3):204-208

Talbert CB, Hyink DM (1988) Implications of genetic improvement for the growth and yield of trees and stands. In: Ek AR, Shifley SR, Burk TE. Forest growth modeling and prediction. Proc IUFRO Conf, USDA For Serv Gen Tech, p 562-571

Tang S, Meng FR, Bourque CP (2001) Analyzing parameters of growth and yield models for Chinese fir provenances with a linear mixed model approach. Silvae Genetica 50(324):140-145

Terrance ZY, Jayawickrama KJ, Clair JS (2010) Realized gains from block-plot coastal Douglas-fir trials in the northern Oregon Cascades. Silvae Genetica 59(1-6): 29-39

Vanclay JK (1995) Models for tropical forests: a synthesis of models and methods. For Sci 41:7-42

Vergara R, White TL, Huber DA, Shiver BD, Rockwood DL (2004) Estimated realized gains for first-generation slash pine (Pinus elliottii var. elliottii) tree improvement in the southeastern United States. Can J For Res 34(12):2587-2600

Vergara R, White TL, Huber DA, Schmidt RA (2007) Realized genetic gains of rust resistant selections of slash pine (Pinus elliottii var. elliottii) planted in high rust hazard sites. Silvae Genetica 56(1-6): 231-242

Wang T, Aitken SN, Woods JH, Polsson K, Magnussen S (2004) Effects of inbreeding on coastal Douglas fir growth and yield in operational plantations: a model-based approach. Theor Appl Genet 108(6): 1162-1171

Wang Y, Wang J, Qi W, Gao X, Wang Q, Zhang P (2015) Effects of Pinus armandi Franch provenances on parameters of height-age models. Journal of Northwest A \& F University (Nat Sci Ed) 43(7):74-81

Wang Y, Wang J, Zhang S, Ma W (2016) Parameters of height-age models for Larix kaempferi provenances. Journal of Northeast Forestry University 44(9):1-4

Weiskittel AR, Kershaw JA, Vanclay JK, Hann DW (2011) Forest growth and yield modeling. Chichester, Wiley-Blackwell, p 415
Weng YH, Kershaw J, Tosh K, Adams G, Fullarton MS (2008) Heightdiameter relationships for jack pine seedlots of different genetic improvement levels. Silvae Genetica 57(1-6):276-282

Weng Y, Park Y, Simpson D, Tosh K, Fullarton M (2010) Tree improvement effects on tree size distributions for Picea glauca and Picea mariana in New Brunswick, Canada. Scand J For Res 25(1):10-20

Westfall JA (1998) Growth models and mortality functions for unthinned and thinned loblolly pine plantations. Virginia Polytechnic Institute and State University

Wu HX (1999) Study of early selection in tree breeding. 2. Advantage of early selection through shortening the breeding cycle. Silvae Genetica 48(2):78-83

Wu HX, Matheson AC (2005) Genotype by environment interactions in an Australia-wide radiata pine diallel mating experiment: implications for regionalized breeding. For Sci 51(1):29-40

Xie C, Yanchuk AD (2003) Breeding values of parental trees, genetic worth of seed orchard seedlots, and yields of improved stocks in British Columbia. West J Appl For 18(2):88-100

Yang Z, Cohen WB, Harmon ME (2005) Modeling early forest succession following clear-cutting in western Oregon. Can J For Res 35(8): 1889-1900

Ye TZ, Jayawickrama K, Clair JBST (2010) Realized gains from blockplot coastal Douglas-fir trials in the northern Oregon cascades. Silvae Genetica 59(1-6):29-39

Zeide B (1993) Analysis of growth equations. For Sci 39:594-616

Zhang S, Burkhart HE, Amateis RL (1997) The influence of thinning on tree height and diameter relationships in loblolly pine plantations. South J Appl For 21(4):199-205

Zheng ZK (2017) Establishment of height-diameter relationship model of Pinus massoniana provenances. Journal of Green Science and Technology 1:5-8

Publisher's note Springer Nature remains neutral with regard to jurisdictional claims in published maps and institutional affiliations. 